\title{
GUSTAVO ROJAS PINILLA: DICTADURA O PRESIDENCIA: LA HEGEMONÍA CONSERVADORA EN CONTRAVÍA DE LA LUCHA POPULAR. ${ }^{2}$
}

\author{
GUSTAVO ROJAS PINILLA: DICTATORSHIP OR PRESIDENCY: THE CONSERVATIVE \\ HEGEMONY IN CONTRAVENTION WITH THE POPULAR FIGHT.
}

Recibido: Febrero 2014 Revisado: Marzo $2014 \quad$ Aceptado: 1 de Mayo 2014

Por: José Fernando Valencia Grajales. ${ }^{1}$

\section{RESUMEN.}

El presente texto derivado de investigación, tiene como objetivo analizar los discursos de Rojas Pinilla y la influencia que tuvo sobre ellos, los aires fascistas de finales del siglo XIX y principios del XX y como crearon enemigos del pueblo, con el fin de justificar su accionar sobre sectores de la sociedad por parte del ejército, como garantizador de un orden social.

\section{PALABRAS CLAVES.}

Ideologia, fascismo, crisis, Rojas Pinilla, dictadura, politica, historia social, subjetividad.

\section{ABSTRACT.}

The current text, derived from a piece of research, aims to analyze the discourses of Rojas Pinilla and the influence played by the fascist hints of the late nineteenth century and the early twentieth century and how they created enemies of the people in order to justify their actions on sectors of society by the army as a guarantor of a social order.

\section{KEY WORDS.}

Ideology; Fascism; Crisis; Rojas Pinilla; Dictatorship; Politics; Social History, and Subjectivity.

\footnotetext{
${ }^{1}$ José Fernando Valencia Grajales: abogado Universidad de Antioquia, politólogo Universidad Nacional de Colombia, especialista en Cultura política: pedagogía de los derechos Humanos Universidad Autónoma Latinoamericana, Magister en Estudios Urbano Regionales de la Escuela de Estudios Urbano Regionales de la Universidad Nacional de Colombia, estudiante del Doctorado en Conocimiento y cultura en américa latina, director y editor revista Kavilando. Docente Investigador Universidad Nacional Seccional Medellin. Medellín-Colombia. Contacto: Jose. valencia@unalmed.edu.co perseo@kavilando.org
} 


\section{Introducción.}

El presente trabajo nace como disertación del grupo Kavilando, dentro de su línea de investigación Historia de las organizaciones sociales y populares, el mismo se realiza dentro del marco metodológico histórico-social y de búsqueda del sujeto histórico que describe el Instituto para el Pensamiento y la Cultura en América Latina (Ipecal), para ello se utilizan los discursos históricos pronunciados por Rojas durante su periodo presidencial, realizando un análisis del discurso, y tomando como referente teórico lo dicho por Gramsi (1999) y Poulantzas (1974) y las percepciones mítico -simbólicas (Eliade, 1979 - 1992).

Los regímenes totalitarios son dificiles de explicar, en especial cuando existen tantos referentes teóricos (Gramsi, 1999) (Rouquié, 1986) (Lipset, 1963) (Arendt, 1982) que pretenden dar explicaciones univocas, por ello es necesario realizar una definición amplia que dé explicaciones contextuales e históricas que puede llevar a graduaciones como dictaduras, autoritarismos y fascismos. Todos ellos se pueden entender dentro de esta lectura como una concepción ideológica que pretende abarcar dentro de su seno la política, el orden, la educación, el pueblo, la economia, la cultura la raza la sangre el honor, el heroísmo, el estado y lo simbólico como mítico. Estas formas que nacen de las visiones hegemónicas, se pueden fundar en el racionalismo, en el alma, en asuntos naturales y formas religiosas que pretenden darle sentido a la racionalidad, al capitalismo, conllevando a reemplazar el individualismo por la unidad nacional, la democracia por el líder político, siempre en pro de la homogenización. En donde se busca la salvación y el sacrificio, allí la política no es una deliberación sino una imposición, solo existe trabajo y cumplimiento (Marcuse, 1978).

\section{La dictadura un concepto en discusión.}

La dictadura es un término dentro de los totalitarismos que por momentos ha sido muy manoseado por los hombres durante el paso de la historia siendo utilizado con fines semánticos diferentes, considerándose en la antigüedad como un orgullo hacia un determinado sujeto, pero que con el desarrollo de la historia se transforma en una especie de insulto que se lleva con vergüenza, además de tener matices, ya que puede ser utilizado con el fin de nombrar a un individuo, a un sistema de gobierno o incluso a un periodo de tiempo. La dictadura proviene del latín dictatūra: la misma se entiende como un sistema de gobierno en la cual el poder se concentra en torno a una sola persona a la que se le denomina dictador. La real academia de la lengua española lo significa de la siguiente manera:

"Dictadura. (Del lat. dictatūra): 1. f. Dignidad y cargo de dictador. 2. f. Tiempo que dura. 3. f. Gobierno que, bajo condiciones excepcionales, prescinde de una parte, mayor o menor, del ordenamiento jurídico para ejercer la autoridad en un país. 4. f. Gobierno que en un país impone su autoridad violando la legislación anteriormente vigente. 5. f. País con esta forma de gobierno. 6. f. Predominio, fuerza dominante. La dictadura de la moda" (Real Academia Española, 2001).

Dicha definición nos lleva a comprender que no existe una percepción univoca y que la misma depende del contexto histórico social. Se ha entendido como parte del "vox populi" que la dictadura y especialmente la latinoamericana como un gobierno que se funda de facto, que no permite la división de poderes y se ejercita la autoridad 
por parte de quien gobierna de forma arbitraria, permitiendo solo el beneficio de la minoría e impidiendo la oposición. Como se observara la palabra dictadura nos conlleva al sujeto dictador que tiene también sus propias connotaciones idiomáticas y que describe la real academia así:

"Dictador, ra: (Del lat. dictatōre[m]): 1. m. y f. En la época moderna, persona que se arroga o recibe todos los poderes políticos extraordinarios y los ejerce sin limitación jurídica. 2. m. y f. Persona que abusa de su autoridad o trata con dureza a los demás. 3. m. Entre los antiguos romanos, magistrado supremo y temporal que uno de los cónsules nombraba por acuerdo del Senado en tiempos de peligro para la república, confiriéndole poderes extraordinarios" (Real Academia Española, 2001).

Se entiende pues que el dictador es quien ha impuesto o sucede a quien o quienes impusieron el Sistema político que permite u obliga a que una sola persona detente el poder de forma casi universal, sin someterse a ningún tipo de leyes, salvo las que él se autoimpuesto, sin límites, e impidiendo la intervención de otros que él personalmente no autorice y controlando todos los aspectos de la vida del Estado y la de sus ciudadanos o miembros.

La dictadura históricamente y conceptualmente no se le ha indilgado exclusivamente solo a los individuos, también se ha utilizado para describir a grupos de hombres que la ejercen tales como junta de militares, cofradias, grupos religiosos, partidos políticos hegemónicos, e inclusive como evolución de la crisis resuelta con pactos políticos entre miembros de diferentes partidos que aseguran para sí, el control del Estado. La dictadura es en sí misma por momentos constitucional, es decir prevista por la constitución en casos de emergencia estatal, es legal, en los casos en que se respalda en una ley, que generalmente expide el congreso o parlamento, popular cuando la misma proviene de un plebiscito, pactista, cuando proviene de un pacto entre miembros de diferentes partidos o entre partidos y militares y finalmente la dictadura de facto que es la que en la historia ha sido la más conocida, comprendida y publica como golpe de estado.

Es por ello que se hace necesario plantear que son las dictaduras, y deconstruir tanto el concepto como las circunstancias políticas, económicas, culturales y sociales que fundan o determinan el campo de cultivo necesario para que la misma se desarrolle, lo cual en ultimas debe de determinar los elementos que expliquen o que describan los elementos principales de una dictadura dentro del marco de una sociedad determinada. Para ellos se ha elegido a Alain Rouquié, como inspirador de las concepciones prescriptivas de lo que una dictadura contiene.

Rouquié, dentro de su texto Dictadores, militares y legitimidad en América Latina, se hace una pregunta similar a la planteada en este texto la cual es:

“¿Cómo definir la dictadura en estados donde la mayoría de las veces no existe un acuerdo mínimo sobre la organización de la vida en común sino más bien antagónicos sistemas de valores y en los cuales "la creencia en el valor social de las instituciones", que define la legitimidad politica (Lipset, 1963 p.89), lejos de estar sólidamente enraizada es objeto de hostilidad o de la indiferencia de importantes sectores de la población?" (Rouquié, 1986, p.11) 
Luego de dicha pregunta el autor entra a definir la respuesta, considerando que la misma, no puede ser de carácter tajante, es decir, que no existen respuestas muy claras o elementos realmente definidos que expliquen que o cuando se está ante una dictadura, ya que el componente que distingue y explica dicha concepción en la mayoría de los casos es una contraposición entre las instituciones y la constitución, razón por la cual Alain explica su respuesta así:

En numerosos estados de América Latina contemporánea no es nada sencillo ponerse de acuerdo sobre el carácter dictatorial o no de un régimen porque en la historia de los mismos no se puede oponer dictadura y orden constitucional, tal como el negro y el blanco, el mal y el bien (Rouquié, 1986, p.11).

Además de lo expresado por este autor, es muy complicado determinar que el poder preexistente sea más o menos legitimo respecto de otros gobiernos que no obstante, ser efimeros causaron grandes daños a una sociedad determinada, o que dicha dictadura a pesar de causar grandes estragos ante una sociedad especifica produzcan grandes satisfacciones a una franja de la sociedad que sostiene dichas formas gubernamentales como buenas.

En fin se podría decir que las dictaduras en Latinoamérica se han caracterizado por ser de carácter heroico, es decir todos quienes se abrogan el derecho de gobernar a sangre y fuego, o de forma pacífica e incluso de forma regular respetando las reglas de juego electoral, lo hacen a nombre de un Dios, de un pueblo, de unos valores, como la paz, el orden, la seguridad, la salvación, la moral, la pureza, la nación, la patria, con el fin de eliminar los enemigos del Estado, la prosperidad, la concordia nacional, la unidad, la gloria e incluso la restauración. Pero todos ellos buscan estos objetivos a costa de la sumisión de otros agentes, miembros o ciudadanos del mismo Estado, y en pocos casos en contra de otras naciones (Mikou, 2007, p.9).

Como se puede observar hasta el momento no se puede decir que el concepto, en sí mismo, entrañe o distinga de forma exacta lo que significa una dictadura o lo que es un dictador, pero si nos acerca a las primeras apreciaciones de lo que más adelante intentaremos ampliar y justificar, como lo son los totalitarismos, para ello se continuara en el siguiente capítulo con las incidencias históricas del término.

\section{Metodologia.}

Para la elaboración del presente texto se ha acudido a:

- Una revisión documental - conceptual en torno al tema en cuestión,

- Análisis de algunas de las más importantes discursos de Rojas Pinilla

- Eventos de discusión y debate en torno al tema, análisis histórico-hermenéutico.

En ese orden de ideas, de manera pedagógica, se presentarán los resultados en tres bloques temáticas así:

- Se presentara un marco teórico,

- Se realizara una contextualización histórica del hecho y

- Se intentaran daran algunas conclusiones respecto de lo ocurrido en aquella época buscando herramientas que permitan hacer lectura del presente a 
propósito del actual y trascendental proceso de negociación entre la guerrilla de las Frac-Ep y el Gobierno de Colombia.

\section{Resultados.}

\section{Dictadura y dictador.}

El termino dictadura y dictador han tenido a lo largo de la historia varias acepciones, la primera nace en Roma y más precisamente en el periodo de la república en el cual con el fin de evitar la concentración del poder, este se divide en "auctoritas, potestas y maiestas".

Las "auctoritas" se encontraban en cabeza del Senado el cual representa el prestigio fundado en el conocimiento y la permanencia. Luego encontramos las "potestas" ubicadas en las magistraturas romanas o "Cursus Honorum Superior" y conocida como la capacidad de "mandar" y finalmente la "maiestas" o la soberanía que se encontraba en el pueblo romano y que se manifiesta en los tribunos y las asambleas entre otras. Para ser magistrado se requería realizar el Cursus Honorum o carrera política, el cual debía llenar los requisitos para ser "magistratus populi Romani" debía ser Ciudadano de pleno derecho, es decir nacido libre, podía estar bajo el poder del páter familias, no podia ejercer ningún oficio servil, ni trabajar a sueldo de nadie, ni haber sufrido una condena judicial, debía haber prestado el servicio militar y haber desempeñado las magistraturas inferiores según el orden establecido y a unas precisas edades. El servicio militar a los 17 años como escolta de un general o tribuno militar; Cuestor a los 30; Edil a los 37; Pretor a los 40 y Cónsul a los 43, además de pertenecer a una familia patricia.

Las magistraturas son el consulado, la pretura, la censura, tribuno de la plebe, edil, la cuestura, todas ellas llamadas ordinarias son anuales, irremovibles durante su periodo, colegiadas, se realizan por parejas, son incompatibles con otros cargos, son de elección, además de ser irresponsables durante su servicio. También existen las magistraturas extraordinarias como la dictadura esta última magistratura es la que nos compete en este escrito y es aquella que confería a una persona, llamada dictadores, una autoridad suprema, un poder absoluto e individual, gobernando con la ayuda de un magíster equitatum que el escogía y quien dirigía y mandaba los ejércitos en su ausencia. El senado designaba dicho magistrado de los propuestos por los cónsules y solo en caso de guerra o crisis civil adquiría el poder, su duración era de 6 meses y al finalizar su periodo debian rendir cuentas al Senado.

La dictadura nació, al parecer a propuesta de Titus Larcius, miembro de una familia etrusca que se estableció en Roma, de acuerdo con Tito Livio (1905, p. 62) es nombrado dictador para hacer frente a la Amenaza de guerra en contra de los latinos, compuesta por treinta personas, exaltadas por Octavio Mamilio, quien pretendió conspirar en contra de Roma para restaurar a Tarquino. Una vez nombrado dictador se unió y nombro como maestro de caballería a Espurio Casio Vecellinus. El dictador es también nombrado "magister populi" durante su periodo se suspendian todos los procedimientos ordinarios, nadie podía criticar, censurar ni discutir las órdenes del dictador. 
El año siguiente -501 a.C.- tuvo como cónsules a Postumio Cominio y Tito Larcio. Durante este año se produjo un incidente que, aunque pequeño en sí mismo, amenazó con llevar a la reanudación de una guerra aún más temible que la Guerra Latina. Durante los juegos en Roma algunas cortesanas fueron raptadas por jóvenes sabinos llenos de lascivia. Se juntó una multitud y se produjo una disputa que se convirtió casi en una batalla campal. La alarma se incrementó al tener conocimiento cierto de que, a instancias de Octavio Mamilio, las treinta ciudades de latinas habían formado una Liga. El Estado se sintió tan atemorizado por situación de tanta gravedad que se sugirió por primera vez que se nombrase un dictador -500 a.C.-. No se puede asegurar, sin embargo, con certeza en qué año fue creada esta magistratura, o quiénes eran los cónsules que habían perdido la confianza del pueblo por su adhesión a los Tarquinios (esto, también, forma parte de la tradición), o quién fue el primer dictador. En la mayoría de los autores antiguos encuentro que fue Tito Larcio y que Espurio Casio fue su jefe de caballería [magistrum equitum, en el original.- N. del T.] (Livio, 1905, p. 62)

La dictadura llego a su máxima expresión, convirtiéndose en lo más semejante a los dictadores de algunos países latinoamericanos, africanos y europeos de nuestra más reciente historia, en la figura de Cayo Julio César (Gaius Iulius Caesar) quien por tener parte de su descendencia en la plebe y ser recién nombrado cónsul, se autonombro dictador sin el consentimiento del Senado pero con la aprobación del pueblo gracias a una ley de tierras, luego se declaró en guerra y conquisto las Galias, la Bélgica, la Aquitania, la Armórica, la Germania, España y la Bretaña entre otras. Fue nombrado dictador perpetuo, cónsul, tribuno, emperador, general en jefe y Pontífice, dirigía los magistrados y tribunos del pueblo, alistaba tropas, declaraba la guerra y hacia la paz. Se convirtió en el político, que con su retórica dominaba al pueblo, y su indulgencia practicaba la beneficencia. Como militar figura como uno de los mejores, y como Dios fue venerado por sus súbditos (Creighton, 1881).

La historia fue corriendo y aparecieron nuevas figuras que se asemejaban a la figura del dictador como concentrador de todos los poderes, los cuales se iniciaron con los reyes europeos, y los estados pontificios que giraban en torno al Papa. Luego de estas figuras nacen las figuras presidenciales o de primer ministro, como concentradores de poder, sin embargo dichas figuras tenian limitaciones de carácter constitucional o monárquico que solo se veían liberadas ante los peligros de la guerra. Pero dichas formas eran llamadas estados de excepción, estados de guerra y guerras declaradas, los cuales se inspiraban en los mismos principios de las magistraturas romanas, hacerle frente a los estados de necesidad manifiesta por guerra y trastornos civiles.

Luego de las guerras de independencia de América y la revolución francesa, no se escuchó más aires de concentración de poder en manos de un solo hombre, hasta la aparición de la constitución de Weimar en Alemania, en dicha constitución en el artículo 48 que ayudo a redactar Max Weber (1972), se le confirieron por vez primera al presidente de un país todos los poderes propios de un dictador, dicho artículo dice lo siguiente:

"Artículo 48: Si un País no cumple los deberes que le impone la Constitución o las leyes del Imperio el Presidente de éste podrá obligarle a ello, con ayuda de la fuerza armada. Cuando se hayan alterado gravemente o estén en peligro la seguridad y el orden públicos en el Imperio, el Presidente puede adoptar las 
medidas indispensables para el restablecimiento de los mismos, incluso en caso necesario con ayuda de la fuerza armada. Con este fin puede suspender temporalmente en todo o en parte los derechos fundamentales fijados en los artículos 114, 115, 117, 118, 123, 124 y 153. El Presidente del Imperio habrá de dar conocimiento inmediatamente al Reichstag de todas las medidas que adopte con arreglo a los párrafos $1^{\circ}$ y $2^{\circ}$ de este artículo. A requerimiento de éste dichas medidas quedarán sin efecto. El Gobierno de un País podrá aplicar provisionalmente en su territorio medidas de las expresadas en el párrafo $2^{\circ}$ de este artículo cuando implique peligro el retraso en adoptarlas. Tales medidas quedarán sin efecto si lo reclaman el Presidente del Imperio o el Reichstag. Una ley del Imperio regulará los detalles" (Weimar, 1919).

Dicho artículo constitucional se verá reforzado en 1922 por Webber en su texto Economía y sociedad (2002) donde dará las pautas del líder carismático que finalmente se convirtió en la herramienta necesaria para que los fascistas utilizaran a futuro. Lo anterior aunado a las disposiciones legales le permitieron a Adolf Hitler (Bullock, 1955) (Rüthers, 2004) convertirse en el primer dictador de nuestra era, y quien al igual que Cesar, surgió de la clase social de estratos bajos, de la industria cervecera, y de forma popular, por medio de los plebiscitos, fue eliminando todos los obstáculos que le impedian mantener un poder absoluto, igualmente como Cesar, logro convertirse en un gran líder militar y conquistar territorios, apropiándose de las riquezas y repartiéndola a los miembros de su selecto grupo de alemanes puros. Situación similar ocurrió en Italia con Benito Amilcare Andrea Mussolini, hijo de un herrero y una maestra y curiosamente con un padre con tendencia socialista, Benito fundamentado en el nacionalismo, el fascismo y el anticomunismo, ataco de frente los movimientos revolucionarios que creaban desorden, como militar logro triunfos en África, con el favor del rey Víctor Manuel III quien lo nombro en 1922, jefe de Gobierno, se abrogo poderes dictatoriales desde 1922 hasta 1943, con una serie de leyes que limitaban o le quitaban derechos a los ciudadanos que gobernaba.

El caso Español tiene nuevamente características similares Francisco Franco Bahamonde, de padre de la marina naval y madre cercana a las lides del mar y descendencia noble, se dedicó a la marina también, como militar cosecho triunfos en Argelia, como político se unió al golpe de Estado de carácter militar llamado "E1 pronunciamiento del 17 y 18 de julio de 1936" el cual se instauro a causa de la victoria del partido frente popular de carácter socialista y comunista, pero fueron repelidos, lo que conllevo a una guerra civil, es por ello que fue envestido como Jefe Supremo del bando sublevado el 1 de octubre de 1936, para luego ejercer como Jefe de Estado de España desde dicha fecha, creo el partido único Falange Española Tradicionalista y de las Jons. Se convirtió en personalización del culto, aglutino diferentes tendencias del conservadurismo, del nacionalismo y del catolicismo opuestas a la izquierda politica y en pro del desarrollo de formas democráticas de gobierno. Como se pueden observar estos tres casos de la actualidad reflejan un poco los casos europeos y describen en las personalidades y actuaciones el cómo ganaron el favor del pueblo y se abrogaron todos los poderes para convertirlos en dictadores.

\section{Gustavo Rojas Pinilla.}

Nace en Tunja el 12 de marzo de 1900 en un hogar humilde pero religioso, se educó como normalista, bachiller y luego cadete en la Escuela Militar de Bogotá donde llego a ser ingeniero civil, teniendo a cargo las carreteras Socha-Támara, Vélez-Chipatá 
y Carare, fue jefe de la fábrica de municiones del ejército, paso a comandante de los grupos de artillería de La Popa y Palacé, fue subdirector de la Escuela de Guerra y director de Aeronáutica Civil. Paso a comandante de las Brigadas Primera y Tercera. En esta última soporto el bogotazo manteniendo a raya las revueltas populares en Cali, esto lo catapulto para que el presidente Ospina lo nombrara ministro de Correos y Telégrafos en pleno desarrollo de las comunicaciones, donde implemento el servicio telefónico con frecuencia modulada, los primeros teléfonos públicos y la telegrafía rápida.

Ante las constantes tenciones entre los liberales, conservadores y la falta de apoyo de su propio partido Ospina se ve forzado a cambiar de cúpula ministerial y dentro de esos cambios, coloca varios militares en el ministerio, nombra a Rojas como comandante general del ejército y cierra el congreso, con la excusa de la violencia y el inminente fraude electoral de realizarse elecciones sin lograrse la modernización de las cedulas. Sin embargo se realizan las elecciones con el candidato único Laureano Gómez quien se hizo a la presidencia y la ejerció de forma autoritaria, promoviendo una Asamblea Nacional Constituyente, en la que intento adoptar un régimen corporativo similar al modelo de España, es decir dentro de estas formas totalitarias de las que se han tocado en este escrito se observan los primeros pinos para convertir al estado en totalitario, y a su presidente un líder que resolvería la crisis. Sin embargo el destino debido a un ataque cardiaco debe dejar el poder en manos de su designado Roberto Urdaneta Arbeláez, quien ejerce bajo las órdenes de Gómez, quien cumplió hasta la exigencia de la renuncia de Rojas que no fue realizada.

Otra de los elementos totalitarios que preparo Gómez para Rojas fue el cerrar el congreso y declarar el estado de sitio, además de eliminar las garantías para la oposición, y mantenerse una violencia generalizada. Es por ello que todas estas circunstancias decantan en una coyuntura que Rojas Pinilla capitaliza en su favor, quien se presenta ante los colombianos, comerciantes, políticos, y elites como un salvador del país. Donde trató de hacer un gobierno sin el apoyo de los partidos tradicionales. Pero con el Gaitanismo, el socialismo de Antonio García, los cristianos independientes de la jerarquía católica y quienes no se sentian identificados con el conservatismo de Laureano, y con algo de apoyo inicial de Ospina, por medio de doña Berta Hernández de Ospina, Gilberto Alzate Avendaño y Lucio Pabón Núñez y el apoyo de los militares,

La brillante carrera militar de Rojas, que logro el grado de teniente general, y que lo hizo presidente o dictador desde el 13 de junio de 1953, nacen a raíz de la violencia bipartidista que se desató con la muerte de Gaitán y que se fue agudizando con la aparición de las guerrillas liberales y comunistas, además de la auto marginación de los liberales de los gobiernos conservadores. El vacío de poder garantizo la eficacia del golpe, pero para perpetuarse en el poder decide llamar a la Asamblea constituyente de Gómez para que legitime el golpe por medio del Acto Legislativo No. 1 del 18 de junio de 1953, que entre otras decreto la vacancia del cargo presidencial y el nombramiento del General Rojas el 13 de junio de 1953 quien ejercería el cargo hasta el 7 de Agosto de 1954, sin embargo, luego de estos hechos coyunturales la Asamblea era frecuentemente cambiada por Rojas y por las tres fuerzas politicas que acordaban su constitución, la cual contaba con una mayoría conservadora del ala de Ospina Pérez. Gracias a la eficiencia del nuevo general, el 15 de Septiembre de 1953, se realiza un armisticio con las guerrillas Liberales, lo que permite que influencie una nueva reelección que iniciaría a partir del 3 de Agosto de 1954. 
Pero estos meramente históricos nos llevan a algunas reflexiones y conclusiones. Las mismas se fundan en las alocuciones presidenciales donde se observa lo que Marcuse llamo la necesidad de un líder carismático que encarna a un héroe que salvara la patria, lo cual se observa entre otras, en la siguiente alocución del año de 1954 al decir:

"desde el 9 de abril hasta el 13 de junio de (1953) la violencia azoto desenfrenadamente a la república inmolando vidas, atropellando honras y destruyendo propiedades, sin más freno que el cansancio físico y la repugnancia por tanta sangre derramada, hasta que Dios, en su infinita misericordia y bondad nos llevó de nuevo a los caminos de la convivencia, iluminándolos magnánimo con la promesa de una paz justa, que recupero para todos los colombianos los destinos de la patria" (Rojas, 1954:p.9)

Como se observa se apela a la patria y a Dios en pro de un camino justo, además de invocar la misericordia y el sacrificio como fin en sí mismo de la construcción de la república. En el mensaje se observan unos tintes de la búsqueda de una nueva forma de controlar de buscar el orden. Pero esto se ve complementado en las siguientes frases:

A nombre de Colombia os pido, os ruego, que permanezcáis unidos para que no seáis los asesinos de la patria y vuestros propios verdugos" (Rojas, 1954:p.48)

En ella se ve complementada y reforzada la alusión a la patria y el cómo debe existir una unidad, una totalidad, no apelando a la razón sino al sentimiento. Pero dichas formas de totalitarismo y dictadura se vieron complementadas con la creación de su propio partido el movimiento de acción nacional (MAN), además del control de la propaganda, accionada por la educación, la televisión y la radiodifusión, así como lo expresa el propio Rojas al decir:

"la radio y la cultura (...) de modo primordial esa función ha de orientarse hacia el perfeccionamiento intelectual y moral de la comunidad, el que descansa el verdadero porvenir de las naciones" (Rojas, 1954:p.22)

"los modernos adelantos de la televisión y la radio son los instrumentos más adecuados para combatir el grave problema del analfabetismo y ensanchar los rudimentarios conocimientos de todo orden que necesitan los ciudadanos a fin de que sea estable y ambicioso el progreso de la nación.” (Rojas, 1954:p.31)

En ellos se vuelve a plantear como se pretende por intermedio de la televisión y la radio educar y generar la propaganda que enardezca a los miembros del pueblo, generándose de alguna manera la imagen del líder que a futuro salva y conduce a la nación de forma heroica. Pero dichas reformas no pararon alli también se observaron con la utilización de regalos y ayudas a las familias pobres. También se observa en la búsqueda del voto femenino, la reforma a la justicia, al congreso, a las elecciones, a la carrera administrativa, la construcción de carreteras, la apuesta a la religión católica, el control económico, la protección de los trabajadores, la colaboración con el sindicalismo, las cooperativas, y todos los estamentos en pro de la unidad nacional, le dan una gran cantidad de pinceladas a la forma en cómo ejerce el gobierno el presidente Rojas Pinilla y que lo hacen identificable con los totalitarismos, aunque parte de su ejercicio sean parte de una herencia de 
Gómez y que sin embargo por momentos se torna populista e inclinado por cortes conservadores y progresistas.

\section{Conclusiones.}

Los dictadores en América Latina ha sido un evento rutinario y han estado en los siguientes periodos: Argentina (1930-1932 José Félix Uriburu; 1943-1946 Arturo Rawson, Pedro Pablo Ramírez y Edelmiro Farrell; 1955-1958 Eduardo Lonardi y Pedro Eugenio Aramburu; 1962-1963 José María Guido; 1966-1973 Juan Carlos Onganía, Marcelo Levingston y Alejandro Lanuss; 1976-1983 Jorge Rafael Videla, Orlando Ramón Agosti y Emilio Eduardo Massera) Bolivia (1839-1843; 1848; 1857 1861 ; 1864-1872; 1876-1879; 1899; 1920-1921; 1930-1931; 1936-1940; 19461947; 1951-1952; 1964-1966; 1970-1982 René Barrientos, Alfredo Ovando Candía, Juan José Torres, Hugo Banzer y David Padilla entre otros) Brasil (1889-1894; 1930-1945; 1964-1985 Getúlio Dornelles Vargas, João Goulart, Castelo Branco y Artur da Costa e Silva, Emílio Garrastazu Médici, Ernesto Geisel y João Baptista Figueiredo) Chile (1924-1925; 1927-1931; 1973-1990 Bartolomé Blanche, Augusto José Ramón Pinochet Ugarte, César Mendoza, José Toribio Merino, y Gustavo Leigh Guzmán) Ecuador (1876-1883; 1935-1938; 1947; 1963-1965: Ramón Castro Jijón, Marcos Gándara Enríquez, Luis Cabrera Sevilla y General Guillermo Freire Posso; 1972-1979 Guillermo Durán Arcentales) Panamá (Manuel Antonio Noriega) Paraguay (1940-1948 José Gaspar Rodríguez de Francia, Carlos Antonio López Yasfrán, Francisco Solano López, Higinio Morinigo Martínez; 1954-1989 Alfredo Stroessner Matiauda) Perú (1842-1844; 1865-1867; 1872; 1879-1881; 1914-1915; 1919-1931 Augusto Bernardino Leguia; 1948-1950; 1962-1963 Manuel Arturo Odría Amorett; 1968-1980 Juan Velasco Alvarado y Alberto Fujimori) Surinam (1980-1988 Dési Bouterse) Uruguay (1865-1868; 1876-1879; 1933-1938 Alberto Demicheli, Aparicio Méndez y Gregorio Conrado Alvarez; 1973-1985 Juan María Bordaberry) Venezuela (1858-1859; 1859-1861; 1861-1863; 1899-1908; 19081935; 1948-1958 Juan Vicente Gómez y Marcos Pérez Jiménez)

El caso de Rojas Pinilla, es un caso emblemático en América Latina, aunque no el único, pero si es una forma recurrente que se dará en Suramérica, esta podría encontrar explicaciones en la colonia misma, en la subjetividad que enmarca el conocimiento histórico (Zemelman, 2006) en el como la herencia, la cultura, la religión, el mito, el idioma, la educación y ante todo la ideología plantada en cada uno de los latinoamericanos, marco el comportamiento a futuro.

Este se enmarca en el miedo, el orden, la culpa, el trabajo, el desarrolloy la acumulación, todos ellos transmitidos de generación en generación, que se ha visto agobiada por aquellos que inicialmente se consideraban conquistadores, superiores, salvadores y humanos. Estos últimos dominan, exigen, asustan, imponen condiciones, marcan metas a cumplir. Mientras aquellos que se han perpetuado en las clases dominadas, continúan con temor, esperando un salvador que se presenta a manera de dictador, de líder, de experto, de profesional o religioso, que lanza un salvavidas para aquellos desamparados que aún no son capaces de pensar por sí mismos y que aún hoy esperan que sean otros quienes decidan por ellos. 
Este caldo de cultivo fundado en crisis, contradicciones, ambivalencias, amigoenemigo, pobre-rico, tonto-inteligente y tradición-modernidad, permite ideologías que impulsan la creación de líderes, salvadores, dictadores, las hegemonías, fascismos, la extirpación del otro diferente, del enemigo, la homogenización del hombre y la deshumanización del hombre mismo. 


\section{Referencias Bibliográficas}

Arendt, Hannah. (1982). Los Orígenes del Totalitarismo. Madrid. Alizanza editorial.

Bergquist, Charles W. (1981). Café y conflicto en Colombia, 1886-1910: la guerra de los mil dias: sus antecedentes y consecuencias. Traducción: Moisés Melo. Biblioteca colombiana de ciencias sociales FAES (4). Medellín. 328 pp.

Bullock, Alan. (1955). Hitler: estudio de una tiranía, México: Biografias Gandesa. 1955, 364 p.

Caro, Miguel Antonio. (1979). Discursos y otras intervenciones en el Senado de la República 1903-1904. Miguel Antonio Caro; Edición, introducción y notas de Carlos Valderrama Andrade. Bogotá: Instituto Caro y Cuervo.

Castro Gómez, Santiago. (2009). Miguel Antonio Caro: el hombre y su obra. Tübingen, Alemania consultado el 01/11/2009 en: http:/ /www.ensayistas.org/ filosofos/colombia/macaro/introd.htm

Córdoba Marinó, Luis. (1998). Apuntes de historia constitucional y política de Colombia. Colombia: Fundación Universidad de Bogotá Jorge Tadeo Lozano. 306p

Creighton, Mandell. (1881). Nociones de historia de Roma. New York. Appleton, 1881. pp. 169 en: http:/ / www.mercaba.org/SANLUIS/Historia/Universal/ 1\%20 -\%20\%C3\%89pocas\%20y\%20temas/Roma/Creighton_-_Nociones_historia_de_ Roma.pdf.

Dávila Ladrón De Guevara, Andrés. (2002). El Frente Nacional y el proceso constituyente de 1991. Bogotá Universidad de Los Andes.

Eliade, Mircea. (1992). Mito y realidad. España. Labor, 228p.

Eliade, Mircea. (1997.) Tratado de historia de las religiones. España. Era. 462p.

Eliade, Mircea. (1979). Imágenes y símbolos. España. Taurus.196p

Galvis, Silvia \& Donadio, Alberto. (2002). El jefe supremo Rojas Pinilla en La Violencia y en el poder. Medellín. Hombre Nuevo Editores. 567p. il.

Grimal, Pierre. (1999). La civilización romana: vida, costumbres, leyes, artes. España, Paidós. 332p.

Gramsci, Antonio. (1999). Cuadernos de la cárcel: Quaderni del carcere (1975). Ed. Era (Univ. de Puebla). México, 1999. Edición crítica del Instituto Gramsci a cargo de Valentino Gerratana. Traducción: Ana María Palos. Revisada por José Luis González. Tomos 1 a 6. 
Jaramillo Castillo, Carlos Eduardo. (1991). Los guerrilleros del novecientos. Colombia. Bogotá: Fondo editorial CEREC. 416 pp.

Lipset, S.M. (1963). L`homme et la politique, Paris, le seuil, 1963, p89 en Rouquié, Alain, Dictadores, militares y legitimidad en América Latina, en Labastida Martin del Campo, Julio, [coordinador] Dictadores y dictaduras, Seminario Regional sobre Dictaduras y Dictadores en América Latina (1986: México) Siglo XXI, Medellín. 239p. pág. 10 a 26, citado en la página 11

Livio, Tito. (1905). Historia de roma desde su fundación [2.18] Libros I a X Ab vrbe condita Traductor: Canon Roberts. Londres. Ernest Rhys. JM Dent \& Sons, Ltd.

Marcuse, Herbert. (1978). Cultura y sociedad. Argentina: Editorial Sur. 126pp.

Mikou, Mohammed. (2007). La novela de la dictadura en el ecuador de los años setenta: la imaginación al servicio de la realidad, Memoria para optar al grado de doctor, Madrid, Universidad Complutense de Madrid, Facultad de Filologia, 2007, ISBN: 978-84-669-3160-1, en: http://eprints.ucm.es/7812/1/T30246. pdf consultado el 01/11/2009, página 9

Nolte, Ernst. (1975). El Fascismo de Mussolini a Hitler, España, Luis de Caralt. 395 p.

Paris Lozano, Gonzalo. (1984). Guerrilleros del Tolima. Bogotá: Publicación Colombia, Áncora.

Poulantzas, Nicos. (1974). Fascismo y dictadura la tercera internacional frente al fascismo. México: Siglo XXI editores.

Real Academia Española. (2001). Dictadura, 22. ${ }^{a}$ edición, 2001, en: http:/ / buscon. rae.es/draeI/ consultado el 01/11/2009.

Rojas Pinilla. (1954). Discursos y mensajes presidenciales. Dirección de información y propaganda del estado. Bogotá: Imprenta nacional. pp. 286.

Roll Vélez, David. (1964). Un siglo de ambigüedad: para entender cien años de crisis y reformas políticas en Colombia. Colombia. Bogotá: IEPRI. 1964.

Rouquié, Alain. (1986). Dictadores, militares y legitimidad en América Latina, en Labastida Martin del Campo, Julio, [coordinador] Dictadores y dictaduras, Seminario Regional sobre Dictaduras y Dictadores en América Latina (1986: México) Medellín: Siglo XXI. 239p. pág. 10 a 26. Pág. 11.

Rüthers, Bernd. (2004). Carl Schmitt en el tercer Reich. Bogotá, Universidad Externado de Colombia.

Serpa Erazo, Jorge. (2008). 1946. Rojas Pinilla una historia del siglo XX pról. Carlos Lemos Simmonds. Bogotá Intermedio. 504 p. il. 
Santos Molano, Enrique. (2006). El 13 de Junio de 1953: las diez horas agitadas de un sábado tranquilo / Enrique Santos Molano. En Revista Credencial historia, No. 197 , p. 3-15

Tirado Mejía, Álvaro. (1989). Nueva historia de Colombia, Historia política. V1: 1886-1946. Colombia. Planeta. 1989. 396 pp. IL.

Weber, Max. (1972). El político y el científico, traductor Aron, Raymond. España: Alianza Editorial. 235 p.

Weber, Max. (2002). Economía y sociedad. Esbozo de sociología comprensiva. Traducción de José Medina Echavarría, Juan Roura Farella, Eugenio Ímaz, Eduardo García Máynez y José Ferrater Mora. Madrid: Fondo de Cultura Económica.

Zemelman, Hugo. (2005). Voluntad de conocer. El sujeto y su pensamiento en el paradigma crítico. México: Anthropos Editorial; Centro de Investigaciones Humanísticas. Universidad Autónoma de Chiapas. Pp.29-36.

Zemelman, Hugo. (2006). El conocimiento como desafio posible. México: Instituto Politécnico nacional, instituto pensamiento y cultura en América latina.

\section{Nota:}

${ }^{2}$ El presente texto es un producto final de la línea de investigación Historia de las organizaciones sociales y populares del grupo de investigación Kavilando. 